\title{
Home-based treatment, vulnerable populations and ethics in psychiatry
}

\author{
K. Glynn ${ }^{1}$ and J. Lyne ${ }^{2}$ \\ ${ }^{1}$ North Dublin Mental Health Services, Ashlin Centre, Beaumont Road, Dublin 9, Ireland \\ ${ }^{2}$ Royal College of Surgeons in Ireland, North Dublin Mental Health Services, Ashlin Centre, Beaumont Road, Dublin 9, Ireland
}

A move away from the institutionalisation that characterised psychiatric care in the early 19th century towards a community-based treatment model for mental illness has represented one of the most important advances in mental health care in the last few decades. This movement has been replicated internationally across several health systems and has contributed to the development of more intensive community-based treatments such as day hospitals and home-based treatment teams. In his editorial on home-based treatment, McGarry (pp. 3-5) emphasises that the widespread implementation of home-based treatment teams in the United Kingdom has been a positive development, with most studies showing a reduction in admission rates and high levels of satisfaction among patients and carers.

A specific recommendation of the Irish mental health policy document, 'A Vision for Change', was the implementation of well-resourced home-based treatment teams, with a view of minimising the need for inpatient treatment. Development of this model has steadily progressed throughout Ireland resulting in substantial improvement in community mental health service delivery; however, implementation has not been universal. A lack of national service evaluation and research has hindered progress further. In this issue O'Keefe and Russell (pp. 7-17) present an allIreland survey of home-based treatment teams using online questionnaires. They report that while these services are viewed positively by the professionals involved, the functioning and staffing levels of these teams vary widely. The authors advocate for an allIreland forum to help define and standardise homebased treatment teams into the future.

A more detailed look at an individual home-based treatment team in North Cork was undertaken by Lalevic et al. (pp. 29-33). They found that the most common reason for referral was affective disorders and that the majority of service users did not require subsequent hospital admission. While further research is evidently needed on home-based treatment teams, these studies point to their positive impact, as well as to the need for more widespread implementation in line with government policy.
The increased prevalence of mental illness among the most vulnerable groups in society is reflected in two papers in the current issue. Hynes et al. (pp. 19-22) took on the challenging task of assessing mental illness among the homeless rough sleepers in Dublin. Of those assessed, they found high rates of severe mental illness, substance misuse and dual diagnosis. In a further study related to this theme, Gulati et al. (pp. 35-45) metaanalysis reports high rates of homelessness on committal to Irish prisons, as well as high rates of psychotic disorder and substance misuse disorders. These two studies draw attention to the complex relationship between mental illness, homelessness and committal to prison, highlighting the need for adequate social care and mental health resources for these vulnerable populations.

The challenge of conducting research on vulnerable populations is considered in an article by Finnegan and O'Donohue (pp. 63-71). The paper reflects on the importance of ethical practices in research, while also highlighting the importance of not excluding vulnerable populations in research. The authors explore methods for overcoming barriers to this important research, which can ensure that vulnerable populations also benefit from any healthcare progress emanating from research endeavours.

Devitt and Kelly (pp. 47-54) also highlight ethical issues among vulnerable populations using recent international examples of institutional abuse, while drawing parallels to the history of abuses committed in some Irish institutions. This provides a stark reminder of what can happen in extreme cases where ethical standards and human rights are ignored. Few could argue against the authors' assertion that human rights and ethics should form a key component in the training and ongoing professional development of all mental health professionals.

Complex ethical and legal issues are reviewed in Gulati et al.'s (pp. 55-60) perspective piece focussing on hunger strikes in prisons. The authors point out that while hunger strikes are rare, there is a dearth of legal guidance for psychiatrists in such circumstances, suggesting that this area requires further scrutiny.

On a lighter note, O'Sullivan et al. (pp. 23-27) demonstrate how Google's Ngram viewer can be utilised to 
explore trends in word usage about themes related to psychiatry over the last 500 years. The study provides fascinating insights into the history of psychiatry, including the relevance of prominent figures in psychiatry, as well as trends in psychiatric terminology across time. Finally, the mental health issues experienced by a modern-day prominent figure is a recurring theme in a book reviewed by Maher (p. 73), who recommends reading Bruce Springsteen's autobiography 'Born to run'.

\section{Conflicts of interest}

K.G.and J.L. have no conflicts of interest to disclose. 